\title{
Multiloculated Mesothelial Cyst: A Diagnostic Dilemma
}

\author{
Srujana*, Rajdeep Singh, Tirlok Chand, Anjali Prakash, Varuna Mallya
}

Department of General Surgery, Radiology and Pathology, Maulana Azad Medical College, 2, Bahadur Shah Zafar Marg, Maulana Azad Medical College Campus, Balmiki Basti, New Delhi, Delhi 110002, India

DOI: $\underline{10.36347 / \mathrm{sasjs} .2020 . \mathrm{v} 06 \mathrm{i} 11.002}$

| Received: 05.11.2020 | Accepted: 17.11.2020 | Published: 23.11.2020

*Corresponding author: Srujana

Abstract

Mesothelial cyst is a rare benign lesion of mesothelial origin. It is usually asymptomatic but may have non specific symptoms. So Accurate diagnosis and optimal management of this condition remains uncertain. Case Report: We report a 14-year-old boy, who presented with abdominal pain and lump. Magnetic Resonance Imaging (MRI) revealed a large well defined multiloculated lesion in retroperitoneum in anterior right pararenal space. The differential diagnosis included benign cystic lesion, lymphangioma, cystic teratoma and duplication cyst. A laparotomy was performed due to his symptoms and size of the cyst. Macroscopically, a $14 \times 10 \times 5 \mathrm{~cm}$ cystic lesion with necrotic fluid and multiple ridges was found. It was resected en bloc. Histology revealed a diagnosis of Mesothelial cyst. The patient recovered well and had no recurrence at 1-year follow-up. Conclusion: Because of rarity and nonspecific symptoms pre operative diagnosis was difficult. Treatment of choice is complete surgical excision.

Keywords: Mesothelial cyst, multiloculated, lymphangioma, cystic teratoma, duplication cyst, necrotic fluid, multiple ridges.

Copyright $@ 2020$ The Author(s): This is an open-access article distributed under the terms of the Creative Commons Attribution 4.0 International License (CC BY-NC 4.0) which permits unrestricted use, distribution, and reproduction in any medium for non-commercial use provided the original author and source are credited.

\section{INTRODUCTION}

Mesothelial cyst is a rare lesion attached to serosal surface of visceral organs. It was initially thought to be cystic lymphangioma, but electron microscopy revealed their origin from mesothelial cells [1]. Immunohistochemical markers like calretinin also distinguish mesothelioma from lymphangioma [2]. They are frequently seen in patients with previous abdominal surgery or pelvic inflammation.

\section{CASE REPORT}

A 14-year-old boy presented with sudden onset of high intensity continuous pricking type of pain in central abdomen for 5 days, after which he noticed a lump of $10 \times 4 \mathrm{~cm}$ in right paraumbilical region. No urinary, bowel or constitutional symptoms were present. On examination he was stable and afebrile, with $10 \times 4$ $\mathrm{cm}$ firm, immobile, non tender, well defined lump limited to right side of umbilical region. No other organomegaly or lymphadenopathy were present.

On Magnetic Resonance Imaging (MRI) there was a large well defined multiloculated lesion in retroperitoneum, in anterior right kidney and extending into right iliac fossa $-14 \times 10 \times 5 \mathrm{~cm}$. It was hyper intense on $\mathrm{T} 1$ and $\mathrm{T} 2$ with no signal suppression suggestive of proteinaceous deposits. It was compressing proximal part of the right ureter leading to moderate hydroureteronephrosis. A provisional diagnosis of benign cystic lesion or lymphangioma or cystic teratoma was kept.

Exploratory laparotomy revealed a large $(14 \times$ $10 \times 5 \mathrm{~cm})$ necrotic fluid filled multiloculated sac adherent to third part of duodenum and right gonadal vessels. The gonadal vessels had to be ligated, and the cyst was separated from inferior venacava and renal vessels. Sharp dissection was needed to separate it from duodenum and paravertebral fascial layers. Intraoperative spillage of necrotic material occurredthis was contained and immediately lavaged. On cut section multiple ridge like projections with necrotic fluid was present. The patient recovered uneventfully and was discharged on postoperative day 3 . He was doing well with no recurrence in 18 months follow up.

Histopathology revealed mesothelial cyst lined by a single layer of flattened cells with flattened nuclei and the cyst wall consisted of fibrous connective tissue. The cyst was confirmed as mesothelial by positive Immunohistochemical reactions using cytokeratin-, AE1/3-, WT1- and calretinin-specific antibodies. 


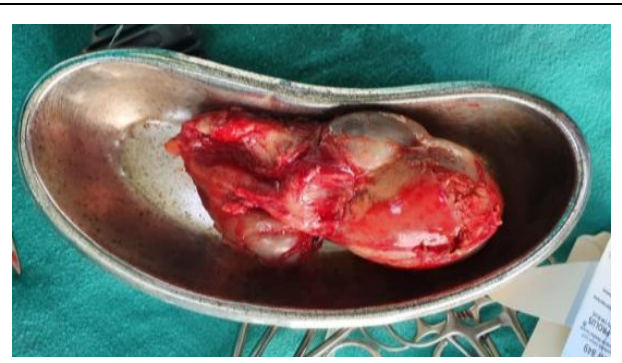

a) Multiloculated resected cystic lesion

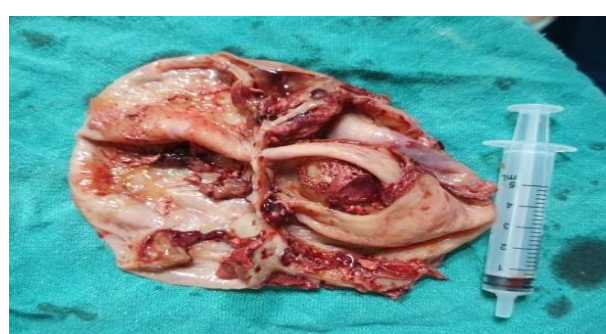

c) Cut section showing septa

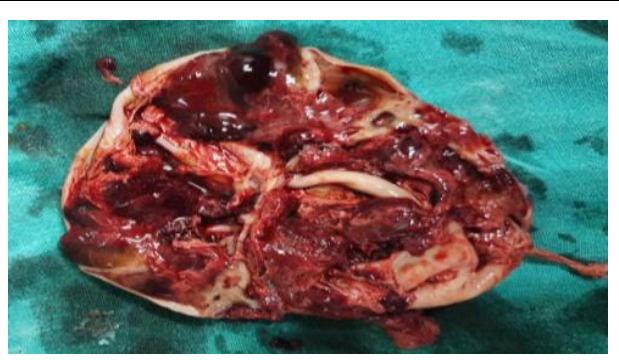

b) Cut section showing ridges with necrotic material

\section{Fig-1: Gross and Microscopic picture of multiloculated mesothelial cyst}

\section{DiSCUSSION}

According to Perrot classification, mesothelial cysts include peritoneal simple mesothelial cyst (PSMC), benign cystic mesothelioma and malignant mesothelioma [3]. The size of PSMC ranges from few centimeters to upto $40 \mathrm{~cm}$ [4]. They usually usually present with increasing abdominal girth, nonspecific abdominal pain, nausea and vomiting due to compression of surrounding structures. Lack of specific symptoms and rarity makes pre operative diagnosis difficult [5]. Clinical examination may show a painless compressible abdominal mass which is mobile transversely. It may be large simulating ascites or ovarian tumour. Complications like rupture, obstruction, infection, inflammation, torsion, hemorrhage or ascites can occur [6].

Mesothelial cyst occurs due to incomplete fusion of mesothelial lined peritoneal surfaces. So it occurs in small bowel, mesentery, mesocolon and omentum [7]. It occurs in children and young adults. Differential diagnoses include cystic neoplasms, lymphangioma, and cystic teratoma [8]. Various imaging modalities can visualize the lesion, but it is difficult to differentiate it from other intra abdominal pathologies [9].

A laparoscopic approach can also be used for excision [10]. However as cystadenocarcinoma is one of the differential diagnosis, spillage should be prevented. Therefore a low threshold for converting laparoscopy to open should be kept.

They are considered benign with excellent prognosis, but there is high recurrence rate [11].
Surgical intervention is best approach for complete removal; a recent study advocated intraperitoneal chemotherapy to reduce recurrence [12]. If mesothelial cyst found incidentally, complete surgical excision is to be done. This is due to small risk of malignancy and to exclude other differential diagnosis.

\section{CONCLUSION}

Mesothelial inclusion cysts remain a rare intraabdominal pathology. We suggest that a safe approach is total en bloc resection, keeping the cyst intact whether this is performed laparoscopically or through open approach, and long term follow - up to assess for recurrence and/or neoplastic transformation.

\section{REFERENCES}

1. Mennemeyer R, Smith M. Multicystic peritoneal mesothelioma: a report with electron microscopy of a case mimicking intra-abdominal cystic hygroma (lymphangioma). Cancer. 1979; 44:6928 .

2. Weiss SW, Tavassoli FA. Multicystic mesothelioma. An analysis of pathologic findings and biologic behavior in 37 cases. Am J Surg Pathol. 1988; 12:737-46.

3. De Perrot M, Brudler M, Totsch M, Mentha G, Morel P: Mesenteric cyst. Toward less confusion?. Dig Surg. 2000, 17: 323-328.

4. Tan JJ, Tan KK, Chew SP. Mesenteric cysts: an institution experience over 14 years and review of literature. World J Surg. 2009, 33: 1961-1965.

5. Patel A, Lefemine V, Ramanand BS: A rare case of a peritoneal cyst arising from the falciform ligament. Cases J. 2009, 2: 134-10.1186/17571626-2-134. 
6. Fernandez Ramos J, Vazquez Rueda F, Azpilicueta Idarreta M, Diaz Aguilar C. Mesothelial giant cyst of great omentum. An Pediatr (Barc). 2009, 71: 180-181.

7. Ros PR, Olmsted WW, Moser RP, Dachman AH, Hjermstad BH, Sohin SH. Mesenteric and omental cysts: histologic classification with imaging correlation. Radiology. 1987, 164: 327-332.

8. Safioleas MC, Constantinos K, Michael S, Konstantinos G, Constantinos S, Alkiviadis K. Benign multicystic peritoneal mesothelioma: a case report and review of the literature. World $\mathbf{J}$ Gastroenterol. 2006; 21:5739-42.

9. Yang DM, Jung DH, Kim H, Kang JH, Kim SH, Kim JH, Hwang HY. Retroperitoneal cystic masses: CT, clinical, and pathologic findings and literature review. Radiographics. 2004 Sep;24(5):1353-65.

10. Theodoridis TD, Zepiridis L, Athanatos D, Tzevelekis F, Kellartzis D, Bontis JN. Laparoscopic management of mesenteric cyst: a case report. Cases Journal. 2009 Dec 1;2(1):132.

11. Elbouhaddouti H, Bouassria A, Mouaqit O, Benjelloun EB, Ousadden A, Mazaz K, Taleb KA. Benign cystic mesothelioma of the peritoneum: a case report and literature review. World Journal of Emergency Surgery. 2013 Dec 1;8(1):43.

12. Sethna K, Mohamed F, Marchettini P, Elias D, Sugarbaker PH. Peritoneal cystic mesothelioma: a case series. Tumori. 2003; 89:315. 